\title{
Water depth, vegetation height and water edge distance are critical in nest-site selection for Grey Crowned Crane at Lake Ol' Bolossat, Kenya
}

\author{
Wanyoike Wamiti ${ }^{1}$, Nathan Gichuki ${ }^{2}$, Dorcas Sigana ${ }^{2}$, Peter Njoroge ${ }^{1}$, Kerryn Morrison ${ }^{3}$, \\ George Ndung' ${ }^{4}$, and Juan Rubalcaba ${ }^{5}$ \\ ${ }^{1}$ National Museums of Kenya \\ ${ }^{2}$ University of Nairobi \\ ${ }^{3}$ Endangered Wildlife Trust \\ ${ }^{4}$ Crane Conservation Volunteers \\ ${ }^{5}$ University of Montana Missoula
}

May 6, 2020

\begin{abstract}
Grey Crowned Crane Balearica regulorum is described as an icon of Africa's wetlands and grasslands and is listed as Endangered on the IUCN Red List of Threatened species. Efforts towards its conservation actions are nonetheless hindered by among others, lack of knowledge on factors influencing breeding productivity such as nest-site selection. Factors influencing the probability of nest-site selection were investigated at Lake Ol' Bolossat, a $43.3 \mathrm{~km} 2$ wetland located in the central Kenya highlands as a breeding resident. The number and distribution pattern of breeding pairs was also determined. A total of 123 breeding pairs were recorded, 103 in the lake and 20 in the surveyed satellite wetlands thus providing the largest database of breeding Grey Crowned Cranes reported in Kenya to date. Mean breeding pair density for the lake's marshes was $6.50 \pm 0.84$ (SE) pairs $/ \mathrm{km} 2$ with a mean distance between nests of $302.53 \pm 17.02$ (SE) m. Generalized Linear Models were used to select the most important environmental variables explaining nest-sites selection. The model selection algorithm yielded a subset of 8 best models, where the most important predictor variables (i.e. those with $\Delta \mathrm{AICc}<2$ ) were determined as water depth (preferred above $50 \mathrm{~cm}$ ), vegetation height (above 60-90 cm) and distance from the water edge $(\mathrm{ca} .100 \mathrm{~m})$. Water depth and vegetation height had positive effects on nesting probability while the distance to water edge exhibits quadratic tendency. These findings provide key insight into Grey Crowned Crane nesting ecology and a basis for breeding habitat modification and management. This study underscores the importance of Lake Ol' Bolossat as a critical breeding site and its significant role in the species' population recovery and survival. The lake should consequently be re-gazetted as a National Park to ensure effective and sustainable control of anthropogenic activities in and around the lake in favour of Grey Crowned Crane.
\end{abstract}

\section{INTRODUCTION}

Knowledge of environmental features that determine habitat quality is critical to developing effective strategies for preserving and restoring natural areas that support species' persistence and recovery (Hobbs, 2003). Nest-site selection is an integrative behavioural process that evolved to maximize reproductive success, adult and young survival. Therefore, understanding what key environmental variables influence nest-site selection in a species is the first step towards an effective management and conservation plan for a focal species or a group of birds such as cranes(Gruidae) (Hobbs, 2003;Swaisgood, Nordstrom, Schuetz, Boylan, Fournier \& Shemai, 2017; van de Loock, 2019).

Nest-site selection starts with the breeding pair or individual choosing where to locate and build a nest. 
Animals such as fish, mammals, reptiles, birds, and invertebrates, must, therefore, choose very carefully where to put their nests for various reasons such as avoiding or reducing risks of predation (Holway, 1991; Götmark, Blomqvist, Johansson \& Bergkvistv, 1995), increase offspring survival (Kolbe \& Janzen, 2002) or in cavitynesters, to maximise ambient illumination (Podkowa \& Surmacki, 2017).Nest-sites are hence an important part of an animal's niche (Gould, 2008), and a major determinant of reproductive success for many organisms since the quality of a nest-site is often linked to a species breeding success (Hatchwell, Russell, Fowlie \& Ross, 1999). It is also a fundamental factor in the survival of a species through generations and is often a poorly understood component of many organisms' reproductive investment (Baden, 2018). Parents must also consider cushioning themselves from predators and factors such as sunlight, wind and precipitation. Species also consider competition (for nesting space and resources such as food) from conspecifics and associates. The choice of a nest-site determines the available resources and threats that the animal and its offspring encounter, making it an important fitness-related decision (Tolvanen et. al. 2018).

While information on the breeding behaviour of most of the 15 extant species of cranes in the world today is available, it is cited as lacking for Grey Crowned Crane Balearica regulorum Bennett 1834(Figure 1). This crane is currently listed as Endangered on the IUCN Red List of Threatened Species as a result of rapid population declines arising from habitat loss and illegal removal of birds and eggs from the wild (BirdLife International 2020). Morrison (2015), describing it as an icon of Africa's wetlands and grasslands where it is resident, has listed factors influencing breeding productivity as an essential knowledge gap that hinder effective implementation of its management and conservation actions across its African range. Further, this author describes this species as an icon of Africa's wetlands and grasslands hence is a key species in the African landscape.

The purpose of this study was, therefore, to contribute to this knowledge gap. Specifically, investigated were the critical features influencing the probability of a nest-site (breeding habitat) selection of the Grey Crowned Crane population at Lake Ol' Bolossat basin, a site holding its second-largest population in Kenya (Wamiti et al., 2019). Also determined were the number, distribution pattern and density of breeding pairs. These findings complement previous studies on the nesting behaviour of Grey Crowned Crane such as Pomeroy (1980a) and Morrison \& Bothma (1998).

\section{METHODS AND MATERIALS}

\section{Study area}

This study was carried out at Lake Ol' Bolossat (0 ${ }^{\circ}$ '24.84"S, 36 25'4.77' E; elevation 2330masl), a 43.3 $\mathrm{km}^{2}$ inland lacustrine wetland located in the central highlands of Kenya in Nyandarua County (Krhoda, 1992)from December 2017 to October 2019. The study was restricted in a block measuring $720 \mathrm{~km}^{2}$. The lake is generally oriented in a north-south direction stretching for c. $30 \mathrm{~km}$. The diversity of vegetation creates a variety of habitats and microhabitats - from open water to perennial marshes. Open water occupies c.23 $\mathrm{km}^{2}$ from the central part towards the south, where the lake is wider $(\mathrm{c} .4 \mathrm{~km})$ and deeper. The rest of the area $\left(\right.$ c. $\left.20 \mathrm{~km}^{2}\right)$ are marshes, dominated by sedges e.g. Cyperus sp., Papyrus sp. (only found in the extreme northern end), and Typha sp., and this is the available habitat for waterfowls such as Grey Crowned Crane that use the marshes for foraging, roosting, nesting and rearing young. These marshes in some parts are characterised by floating bogs that shift positions depending on strength and direction of prevailing winds.

The lake basin and riparian grasslands are heavily encroached and grazed throughout the year, with the number of livestock increasing tremendously during the dry season (usually from December to March). The study area falls within an equatorial type of climate receiving a bimodal rainfall pattern as described by Brown \& Britton (1980). However, this pattern is no longer predictable due to the effects of climate change as experienced from field observations during the study period. The lake has a history of drying up leaving scattered pools of water, the last such time being in 1992 (Gichuki \& Gichuki, 1998). The study area has over 120 man-made or natural wetlands. Twenty of these, whose areas varied from 0.042 ha $\left(420 \mathrm{~m}^{2}\right)$ to 211 ha, were part of this study.

The lake shoreline was divided into sections (breeding sites) described using the local village names. Clock- 
wise, these sites include Ziwani, Mairo-Inya, Githungucu, Kanguyo, Ngurumo, Makereka, Iria-Ini, Gakoe, Kirima, Mugathika, Mukindu, Bahati, Karandi, Fuleni, Gatumbiro, Kanguu and Kianjata.

\section{Nest searching and mapping of breeding pairs}

Collecting data on nesting waterfowls involves potential disturbance to nesting birds, whether direct (handling eggs) or indirect (walking near birds on nests) as reported by Austin \& Buhl (2008). Grey Crowned Crane nests are described as difficult to locate from the ground (Morrison \& Bothma, 1998). With these considerations, nests were not actively searched as this would have likely resulted to trampling on vegetation in the breeding habitats, cause disturbance to nesting waterfowls and expose clutches and chicks to egg poachers who frequent the breeding sites- nests were thus visited once. Location of nests was discerned from cues of a nesting pair behaviour (e.g. when an individual was observed going for a nest relief), and from information obtained from volunteer fishermen and herdsmen. Binoculars and telescopes were additionally used to scan marshes for incubating cranes.

A pair was considered as occupying a breeding territory if i) was frequent within a specific section of the lake or man-made wetland; ii) was known to have bred in the site in the past, iii) was observed gathering nesting material and building a nest, iv) the male aggressively confronted conspecific males, often involving a brief fight and chase, and v) a pair was observed driving out a juvenile (as a sign of re-nesting). Mapping of breeding pairs was restricted to one week in December 2018, the peak of the breeding season in a normal local weather pattern, and repeated two weeks later to confirm positions of breeding pairs as being territorial. Newly appearing pairs afterwards and showing territorial behaviour were not considered (Bradter, Gombobaatar, Uuganbayar, Grazia, \& Exo, 2005).Flocks did not account for territorial breeding pairs and were often found in fields at some distance from the lake. In this study, breeding season was considered as the period between lying of the first clutch and the time when the last chick fledged, this period approximately lasting 13 months for the current study from early-April2018 to mid-April 2019.

\section{Nest-site measurements}

The design employed in this study was a stratified case-control with actual nest-sites as the cases, and random nest-sites as the controls, and strata defined by the sampled wetlands within and outside of the lake basin (Maxson, Fieberg \& Riggs,2008). Data at each nest-site followed descriptions of various authors such as Dwyer \& Tanner (1992) and Wu, Zha, Zhang \& Yang (2009).

The following four variables were measured (or assessed)at each active nest-site(one having an egg and/or chick), as well as at the random nest-sites: mean water depth and mean vegetation height- over four samples (at each cardinal direction) at $1.5 \mathrm{~m}$ from the centre of the nest, distance from the water edge, and grazing intensity (see criteria below). A random nest-site for each active nest was selected to compare characteristics of active nests (presence) with those of randomly-selected sites, also known as unused areas or absent nests. The random nest-sites were placed arbitrarily at $15-25 \mathrm{~m}$ in any direction of the actual nest.

Grazing intensity score was assessed around the nest as either i) none (no faecal remains, vegetation intact, no spoors), ii) low (scattered faecal remains, vegetation slightly grazed, scattered spoors),iii) medium (faecal remains evident, vegetation grazing more evident) or iv) high (faecal remains around the nest, dense spoors and intensive grazing evidence).

\section{Statistical analyses}

Generalized Linear Models were chosen assuming binomial family and logit link function to investigate how the probability of nesting (1, presence of nest vs 0 , absence of nest) is influenced by water depth, vegetation height, distance to the water edge, grazing intensity, and their pair-wise interactions. Tests for potential nonlinear relationships with each of the predictor variables by introducing their quadratic terms in the models and comparing their Akaike's Information Criterion (AICc corrected for small sample sizes; Burnham \& Anderson, 2002) were carried out. Test for multi-collinearity (using the Variance Inflation Factor, VIF) and over dispersion in all models, as well as log-transformation of all predictor variables, were carried out to normalize their residuals. 
The importance of different predictor variables for nest-site selection was investigated using multi-model inference methods (Burnham \& Anderson, 2002). First, the set of best candidate models were computed (i.e. those with $\Delta \mathrm{AICc}<2)$ using an automatic model selection algorithm, and then derived the importance of each predictor variable by summing the AIC weights of the models where this variable is included (Burnham \& Anderson, 2002). The average predictions were computed over the set of candidate models to analyse the relationship of nesting probability with each of the most important predictor variables. All of the above analyses were conducted in R v3.5.3 (Barton, 2019; R Core Team, 2019). The density of breeding pairs was computed as several breeding pairs per unit area $\left(\mathrm{km}^{2}\right)$ of marshes where Google Earth Pro "Add Polygon" tool was used to approximate the marshes area.

\section{RESULTS}

\section{Factors influencing nest-site selection}

A total of 33 nests (all located in wetlands varying levels of standing water) and an equal number of randomly selected nest-sites were accessed and measured. Correlation between predictor variables (water depth, vegetation height, distance to the water edge and grazing intensity) were first considered for analysis to test for multicollinearity (prediction with a substantial degree of accuracy). The VIF values were low $(<1.3)$, and therefore all predictor variables were included in the model without correcting for multicollinearity. The model selection algorithm yielded a subset of 8 best models, where the most important predictor variables (i.e. those with $\Delta \mathrm{AICc}<2$ ) were determined as i) water depth, ii) vegetation height, and iii) distance of nest location from the water edge (Figure 2). Water depth and vegetation height had positive effects on nesting probability while the distance to water edge exhibited a quadratic tendency (Figure 3).

\section{Distribution pattern and densities of breeding pairs}

Breeding pairs distribution in the lake mostly occurred in clusters (clumped) in local breeding sites such as Kianjata, Makereka, Kirima and Fuleni (Figure 4). In other parts of the lake, pairs were randomly distributed in a linear manner where the marshes breadth was narrow (100-500 m wide) such as Ziwani/Mairo-Inya and Kanguu.

A total of 123 breeding pairs were mapped during the 2018/2019 breeding season. A hundred and three (103) of the pairs were in the main lake while the rest (20) were in the satellite wetlands, most of which are man-made reservoirs in private land (Figure 4). It is, however, important to note that only $61 \%$ and $80 \%$ of the mapped breeding pairs attempted breeding (where the pair was observed as at least incubating) in the lake and satellite wetlands respectively. Overall, $64 \%$ of the 123 breeding pairs attempted breeding during the season in consideration.

Dividing the lake into 3 sections each c.10 km long, the highest number of breeding pairs were in the middle section (52) followed by the southern section (32) while 19 were in the north. The average density of breeding pairs in the lake's marshes was $6.50 \pm 0.84(\mathrm{SE})$ pairs $/ \mathrm{km}^{2}$. The highest density was recorded in the middle section breeding sites at $7.14 \pm 1.64$ pairs $/ \mathrm{km}^{2}$ closely followed by the southern section at $7.10 \pm 1.10 \mathrm{pairs} / \mathrm{km}^{2}$ while the lowest density was in the northern section at $4.76 \pm 1.28$ pairs $/ \mathrm{km}^{2}$.

The mean distance between any two neighbouring breeding pairs was $302.53 \pm 17.02$ (SE) $\mathrm{m}$, and a minimum and maximum of $47 \mathrm{~m}$ and $759 \mathrm{~m}$ respectively. A majority $(n=20)$ of the breeding pairs' positions were in the range of 201-280 m (Figure 5). These distances were however observed to vary in different clusters of nests in the north, middle and south sections of the Lake, and would be expected to vary in different breeding seasons as new pairs take up territories and conditions in the breeding habitat change.

\section{DISCUSSION AND CONCLUSION}

\section{Factors influencing nest-site selection}

Grey Crowned Cranes in and around Lake Ol' Bolossat bred in the main lake and small man-made wetlands surrounded by a high influx of human activities such as water abstraction for irrigation and domestic use, livestock grazing, and crop farming. The sizes of these man-made wetlands (0.042 - 87 ha) are smaller 
compared to minimum wetland size observed in South Africa of 162 ha (Morrison \& Bothma, 1998). This observation have the same opinion with Morrison \& Bothma (1998) that the choice of a nesting site by cranes, in general, is less dependent upon human impact, and particularly the Grey Crowned Crane that appears to tolerate human interference. The use of small wetlands in human-dominated landscapes within our study area could as well be an indication of deterioration of breeding sites elsewhere, and that cranes are desperate for suitable breeding sites.

This study has established that there are three important variables that Grey Crowned Cranes consider in the choice of a wetland for a nest-site location. The result strongly suggests that this species select wetlands with water of at least $50 \mathrm{~cm}$ deep, tall vegetation $(60-90 \mathrm{~cm})$ and place their nests at least $100 \mathrm{~m}$ from the edge of the wetland. However, distance to the water edge showed a quadratic tendency perhaps because only a small sample size of nests beyond $100 \mathrm{~m}$ distance were accessed. Water depth is also important as a good predictor of invertebrate abundance (Smith \& Smith, 1988), on which cranes feed their chicks.

In Mongolia, Bradter et al. (2005) reported livestock grazing as potentially harming White-naped Cranes by degrading their breeding habitat and disturbing breeding birds. Grazing was as well observed as a potential direct contributor to nest loses in the Sandhill Crane (Ivey \& Dugger, 2008). Although the effect of grazing was not detected in this study, grazing is considered as an important factor in cranes breeding success. Possible lack of significant results was from a lack of statistical power (e.g. grazing intensity was measured as a categorical variable that may have had a bias). Grazing is known to affect waterfowls in several ways such as pair numbers, nesting densities and nesting success (Kirsch, 1969). Grazing pressure could also result in the succession of vegetation composition and a structure that is less suitable to Grey Crowned Crane (Morrison, 2015). The results show that vegetation height is a key variable affecting nest-site selection and since grazing affects vegetation height, cranes will likely avoid areas of high grazing intensity as a nesting-site.

Findings of this study provide valuable insight into breeding ecology and habitat requirements of Grey Crowned Crane. They can be utilised as a basis for modification and management of crane's breeding habitat such as manipulation or improvement of wetlands to attract a breeding pair(s). In degraded wetlands, for instance, a weir could be constructed or raised to ensure that the water held back reaches at least $50 \mathrm{~cm}$ in-depth in the shallow end. Low-level grazing or exclusion of large herbivores (such as buffalos, elephants, cattle, donkey etc) would naturally allow vegetation to regenerate and flourish on its own, and this can be achieved by fencing small to medium-sized wetlands, natural spring marshes or parts of extensive wetlands with a chain-link or an electric fence in conservation areas. Besides, this information can be adopted in legal documents such as Integrated Management Plans, National Wetlands Policy and International Single Species Action Plans.

\section{Distribution pattern and density of breeding pairs}

The varying breeding pair densities across the lake suggest variance in availability and abundance of food resources. Even though Brown \& Britton (1980) describe food supply in perennial wetlands as probably stable, they disagree that it is not the overriding ultimate factor, and could therefore potentially affect breeding densities. In the current study, it has been shown that other factors are determining this density, the critical one being the suitability of a nest-site. The density observed is possible from the vastness of Lake Ol' Bolossat marshes across a $30 \mathrm{~km}$ stretch, supported by a rich diversity of widespread satellite wetlands (over 120 in the study area), providing a favourable breeding environment sites for occupation by breeding Grey Crowned Cranes. Other than being an indication of the suitability of a wetland as a preferred choice for a breeding site, a high breeding density might moreover be a suggestion of degradation of breeding habitats, increased poaching, disturbances and threats in other breeding sites forcing cranes to seek and congregate in a few sites that are still relatively safe or offering desirable conditions.

Considering only the marsh area (and not the entire wetland area), an average breeding density of $6.50 \pm 0.84$ (SE) pairs $/ \mathrm{km}^{2}$ demonstrate the importance of Lake Ol' Bolossat as a key breeding site for the Endangered Grey Crowned Crane. As observed on the ground, absence of disturbances from livestock and humans would very likely lead to the occupation of more breeding territories in the extensive marshes since the minimum 
distance between neighbouring breeding pairs in this study was observed to be c.50 m. However, as the wetland assumes management following its gazettement as a Protected Wetland Area in July 2018 and the drafting of an integrated management plan, breeding density is expected to rise in the future.

As pointed out earlier, information on the features of a Grey Crowned Crown breeding habitat has been reported as extremely lacking, and therefore an essential and high priority knowledge gap (Morrison, 2015). The breeding pair density reported in this study contributes to this knowledge gap in terms of breeding habitat requirements, number of breeding pairs and an accurate estimate of the amount of suitable breeding sites available at Lake Ol' Bolossat. The results of this study compare reasonably with that of greater sandhill cranes (Grus canadensis tabida) that had an average density of $5.25 \pm 0.36$ nests $/ \mathrm{km}^{2}$ and an average distance between nests at $222 \pm 70 \mathrm{~m}$ (Barzen, Su, Lacy, Gossens \& Moore, 2016)

The breeding pairs occur all around the lake except along a $4 \mathrm{~km}$ stretch between Bahati and Karandi villages on the south-western shores (see Figure 4). This section is characterised by a steep shoreline of open water with violent waves, a dense $1 \mathrm{~m}$ tall tussock grass consociation of Pennisetum spacelata thus presenting a high-risk foraging area for cranes and their chicks. The riparian grassland here too is dominated by heavily grazed fields in some parts in addition to a complete lack of marshes along the shore that breeding pair of cranes require.

In the study area, Gatumbiro and Kianjata breeding sites had the largest area of marshes and were hence expected to have the highest density of breeding pairs but surprisingly had the least densities. This could be attributed to the fact that Gatumbiro is largely a floating marsh that changes position from time to time besides a high traffic of fishermen on canoes or plastic drum rafters and a busy quarry in the heavily encroached and settled riparian grassland creating a disturbance. On the other hand, Kianjata marshes are spread out and stable in terms of vegetation (nest substrates), security and shelter from the continuous cover of sedges exceeding $1 \mathrm{~m}$. However, the marshes are frequented by a large number of livestock, fishermen, and poachers and were recently subdivided into smaller parcels that now present an unfavourable landscape dominated by homes and barbed wire fences.

Breeding densities at Lake Ol' Bolossat in different breeding seasons deserves to be determined to establish the lake's carrying capacity. Breeding densities in other wetlands across the species range in Africa would also require to be established for identification and protection of key breeding sites. These sites will be of great magnitude in the long-term population recovery plans. In eastern Africa, where the population is still described as rapidly declining, it is paramount that efforts are made to understand the activities surrounding all known and/or potential breeding sites and address the challenges, if any, at the local/site level. Information on breeding sites, challenges and breeding densities would ultimately need to be captured in conservation plans for the species.

Given its prominent significance as a key breeding site for an Endangered species alongside the presence of other globally-threatened bird species (e.g. the Endangered Sharpe's Longclaw Macronyx sharpei ), rare plants and an inadequately studied biodiversity, we propose that Lake Ol' Bolossat be accorded a higher protection status i.e. be re-gazetted as a National Park. This will ensure sufficient control of undesirable anthropogenic activities especially poaching and control on the degradation of the wetland and riparian land conditions.

\section{ACKNOWLEDGEMENTS}

This research received funding from African Bird Club (Conservation Award), Leiden Conservation Foundation (African Fund for Cranes courtesy of the International Crane Foundation/Endangered Wildlife Trust Partnership) and activities of a CEPF-funded project to Crane Conservation Volunteers (CCV). The first author was granted an in-kind support of field equipment from IdeaWild (Denver, CO., USA), Werner Schröder (NABU, BirdLife Germany), Dr Günter Nowald (Crane Information Centre, Germany) and Ted \& Darcy Thousand (Baraboo, WI, USA). Dr George Archibaldand Betsy Didrickson (International Crane Foundation, Baraboo, WI) availed relevant literature. The authors are grateful to Kenya Wildlife Service for authorizing this research (No. KWS/BRM/5001), and to the National Museums of Kenya and the University 
of Nairobi for endorsing it.

\section{CONFLICT OF INTEREST}

None declared

\section{AUTHOR CONTRIBUTIONS}

WW developed the study concept (design, objectives, field techniques, data analysis) and led in the acquisition of data. NG, DAS and PN provided critical review of the concept and manuscript to ensure a high level of intellectual content. KM facilitated data acquisition and reviewed the manuscript. GN participated in nests searching and data acquisition. JGR assisted with data analysis, interpretation of results and review of the manuscript.

\section{DATA ACCESSIBILITY}

Data will be uploaded to DRYAD upon manuscript acceptance. However, this being an Endangered species currently facing rampant threats such as eggs and chicks collection at the study site, we kindly request for guidance on nature of data that could be considered as sensitive or granting a waiver of this requirement.

\section{ORCID}

W. Wamiti : https://orcid.org/0000-0001-7300-2101

\section{REFERENCES}

Austin, J.E. \& Buhl, D.A. (2008). Responses of nesting Sandhill Cranes to research activities and effects on nest survival. North American Crane Workshop Proceedings. Retrieved from http://digitalcommons.unl.edu/nacwgproc/156

Baden, A.L. (2018). A description of nesting behaviours, including factors impacting nest site selection, in black-and-white ruffed lemurs (Varecia variegata ). Ecology\& Evolution, 9: 1010-1028.

Barton, K. (2019). MuMIn: Multi-Model Inference . R package version 1.43.6. Retrieved from https://CRAN.R-project.org/package=MuMIn

Barzen, J.A., Su, L., Lacy, A.E., Gossens, A.P. \&Moore, D.M. (2016). High nest density of sandhill cranes in central Wisconsin.Proceedings of the North American Crane Workshop , 13:13-24.

BirdLife International. (2020). Species factsheet: Balearica regulorum . Retrieved from http://www.birdlife.org.

Brown, L.H. \& Britton, P.L. (1980). The Breeding seasons of East African Birds . East African Natural History Society, Nairobi.

Burnham, K.P. \& Anderson, D.R. (2002). Model Selection and Multimodel Inference: A Practical Information-Theoretic Approach. Springer.

Bradter, U., Gombobaatar, S., Uuganbayar, C., Grazia, T.E. \& Exo, K-M. (2005). Reproductive performance and nest-site selection of White-naped Cranes Grus vipio in the Ulz river valley, north-eastern Mongolia. Bird Conservation International , 15: 313-326. DOI: 10.1017/S0959270905000663

Dwyer, N.C. \& Tanner, G.W. (1992). Nesting Success in Florida Sandhill Cranes. The Wilson Bulletin , 104(1): 22-31. Retrieved from http://www.jstor.org/stable/4163113.

Gichuki, N. \& Gichuki, C. (1998). Lake Ol Bolossat. Kenya Past and Present, 30(1): 25-28.

Gotmark, F., Blomqvist, D., Johansson, C.F. \& Bergkvistv, J. (1995). Nest Site Selection: A trade-off between concealment and view of the surroundings? Journal of Avian Biology , 26(4): 305-312.

Gould, J.L. (2008). Cognition and Behavioural Ecology. In: S.E. Jorgensen \& B.D. Fath, (Eds). Encyclopedia of Ecology , pp.668-672. Academic Press. 
Hatchwell, B.J., Russell, A.E., Fowlie, M.K. \& Ross, D.J. (1999). Reproductive success and nest-site selection in a cooperative breeder: effect of experience and a direct benefit of helping. The Auk, 116(2): 355-363.

Hobbs, R.J. (2003). Ecological management and restoration: assessment, setting goals and measuring success. Ecological Management $\&$ Restoration, 4(Supplement), S2-S4.

Holway, D.A. (1991). Nest-site selection and the importance of nest concealment in the Black-throated Blue Warbler. TheCondor, 93(3): 575-581.

Ivey, G.L \& Dugger, B.D. (2008).Factors Influencing Nest Success of Greater Sandhill Cranes at Malheur National Wildlife Refuge, Oregon. Waterbirds , 31(1): 52-61.

Kirsch, L.M. (1969). Waterfowl Production in Relation to Grazing. Journal of Wildlife Management , 33(4): 821-828.

Kolbe, J.J. \&Janzen, F.J. (2002). Impact of nest-site selection on nest success and temperature in natural and disturbed habitats.Ecology , 83(1): 269-281. DOI: 10.2307/2680137.

Krhoda, G.O. (1992). The Hydrology and Function of Wetlands. In S.A. Crafter, S.G. Njuguna \& G.W. Howard (Eds), Wetlands of Kenya,pp.13-22. Gland, IUCN.

Maxson, S.J., Fieberg, J.R. \& Riggs, M.R. (2008). Sandhill Crane nest habitat selection and factors affecting nest success in Northwestern Minnesota. North American Cranes Workshop Proceedings, No. 186. Retrieved from http://digitalcommons.unl.edu/nacwgproc/186.

Morrison, K.L. \& Bothma, J.P. (1998). Wetland nesting sites of wattled and grey crowned crane on the Steenkampsberg Plateau, South Africa.South Africa Journal of Wildlife Research , 28(4): 110-170.

Morrison, K. (2015). (Ed.) International Single Species Action Plan for the Conservation of the Grey Crowned Crane Balearica regulorum. AEWA Technical Series.

Podkowa, P. \& Surmacki, A. (2017). The importance of illumination in nest site choice and nest characteristics of cavity nesting birds.Scientific Reports , 7: 1329. DOI: 10.1038/s41598-017-01430-y

Pomeroy, D.E. (1980a). Aspects of the ecology of Crowned CranesBalearica regulorum in Uganda. Scopus, 4: 29-35.

R Core Team.(2019). R: A language and environment for statistical computing . Vienna, Austria: $\mathrm{R}$ Foundation for Statistical Computing. Retrieved from https://www.R-project.org/

Smith, B. \& Smith, W.P. (1988). Environmental criteria for nest site selection by Mississippi Sandhill Cranes. Proceedings of the Annual Conference of Southeast Association of Fish and Wildlife Agencies , 42: 431-442.

Swaisgood, R.R., Nordstrom, L.A., Schuetz, J.G., Boylan, J.T., Fournier, J.J. \& Shemai, B. (2017).A management experiment evaluating nest-site selection by beach-nesting birds. Journal of Wildlife Management , 82(1):192-201.

Tolvanen, J., Seppanen, J-T, Monkkonen, M., Thomson, R.L., Ylonen, H. \& Forsman, J.T. (2018). Interspecific information on predation risk affects nest site choice in a passerine bird. Evolutionary Biology , 18: 181. Retrieved from https://doi.org/10.1186/s12862-018-1301-3.

van de Loock, D.(2019). Life-history strategies of a facultative cooperative breeder in a fragmented Afrotropical cloud forest. PhD Dissertation. Antwerp, Belgium.

Wamiti, W., Mwangi, J., Fox, D., Bakari, N., Schroder, W., Nowald, G., Walter, B., Ndung'u, G., Bii, E., Wanjala, M., Nekesa, V., Waiguchu, G. \& Kimani, D. (2019). Kenya's first countrywide census of Grey Crowned Crane Balearica reguloram: February-March 2019. NABU Technical Report. Berlin, Germany.

Wu, H., Zha, K., Zhang, M. \& Yang, X. (2009). Nest site selection by Black-necked Crane Grus nigricollis in the Ruoergai Wetland, China. Bird Conservation International , 19: 277-286. 


\section{TABLE}

Table 1: Variable values of the best candidate models $(\Delta \mathrm{AICc}<2)$ including distance to water edge (DWE), vegetation height $(\mathrm{VH})$, water depth $(\mathrm{Wd})$ and grazing intensity $(\mathrm{Gr})$. Bolded figures indicate significant predictor variables at $p<0.05$.

\begin{tabular}{llllllllllll}
\hline $\mathrm{DWE}$ & $\mathrm{VH}$ & $\mathrm{Wd}$ & $\mathrm{DW}^{2}$ & $\mathrm{Gr}$ & $\mathrm{DWE} \times \mathrm{VH}$ & $\mathrm{Gr} \times \mathrm{Wd}$ & $\mathrm{VH}^{2}$ & $\mathrm{Wd}^{2}$ & $\mathrm{DWE} \times \mathrm{Gr}$ & $\Delta \mathrm{AICc}$ & Weight \\
\hline 1.04 & $\mathbf{0 . 9 8}$ & $\mathbf{3 . 1 1}$ & - & - & - & - & - & - & - & 0.00 & 0.22 \\
6.81 & $\mathbf{1 . 1 1}$ & $\mathbf{3 . 5 3}$ & -0.73 & - & - & - & - & - & - & 0.28 & 0.19 \\
10.96 & $\mathbf{1 . 3 4}$ & $\mathbf{5 . 3 8}$ & -1.20 & 11.35 & - & -2.11 & - & - & - & 1.16 & 0.12 \\
4.70 & 3.55 & $\mathbf{2 . 8 6}$ & - & - & $\mathbf{- 0 . 6 5}$ & - & - & - & - & 1.36 & 0.11 \\
31.23 & $\mathbf{9 . 5 8}$ & $\mathbf{6 . 8 1}$ & $\mathbf{- 1 . 8 4}$ & $\mathbf{2 1 . 9 4}$ & $\mathbf{- 2 . 3 0}$ & $\mathbf{- 2 . 5 1}$ & - & - & $\mathbf{- 2 . 4 3}$ & 1.83 & 0.09 \\
0.99 & $\mathbf{- 2 . 1 1}$ & $\mathbf{2 . 9 9}$ & - & - & - & - & 0.29 & - & - & 1.90 & 0.09 \\
7.67 & $\mathbf{1 . 1 1}$ & -6.94 & -0.83 & - & - & - & - & 0.95 & - & 1.90 & 0.09 \\
1.06 & $\mathbf{0 . 9 8}$ & -4.38 & - & - & - & - & - & 0.67 & - & 1.91 & 0.09 \\
\hline
\end{tabular}

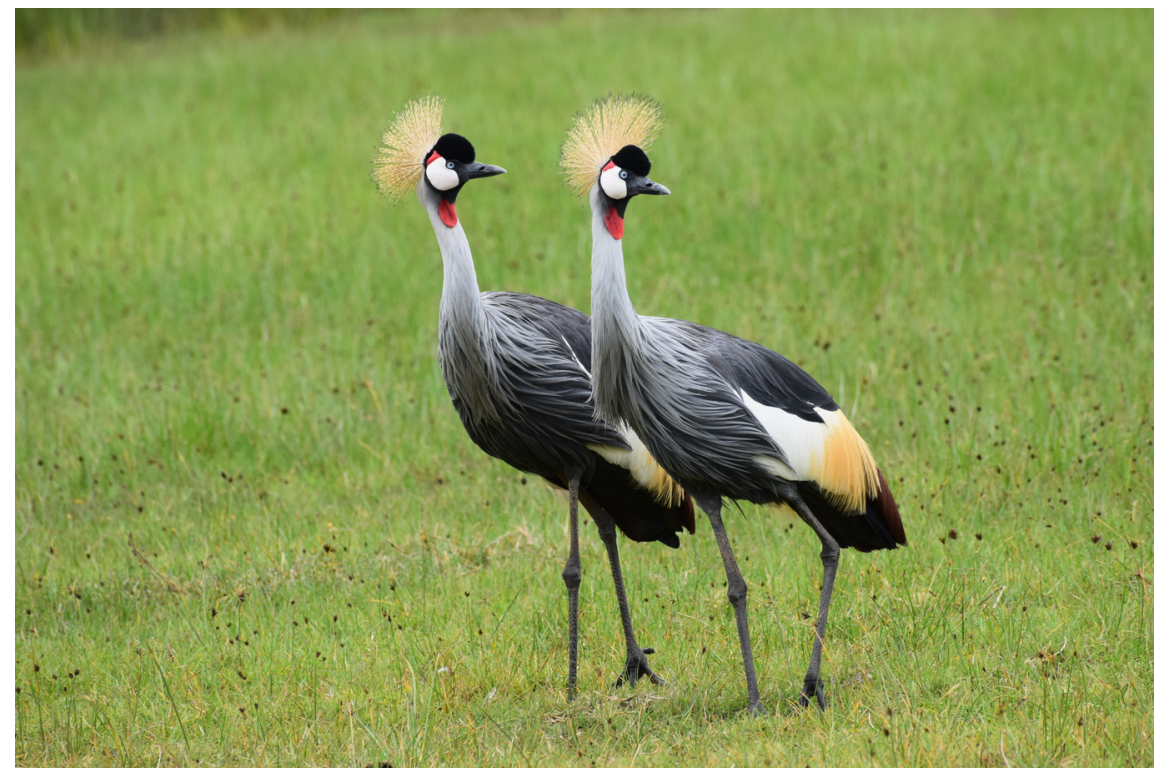



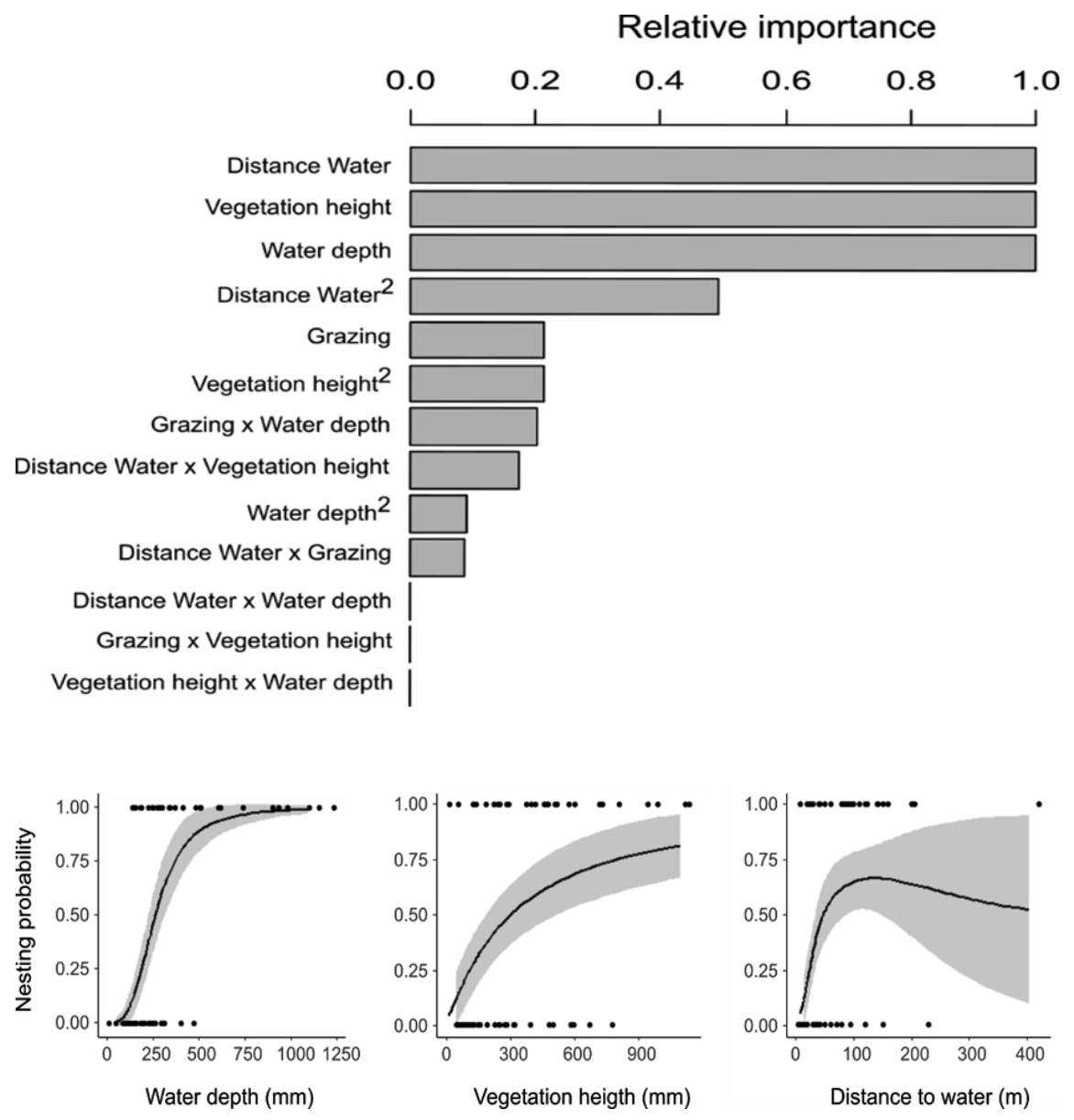


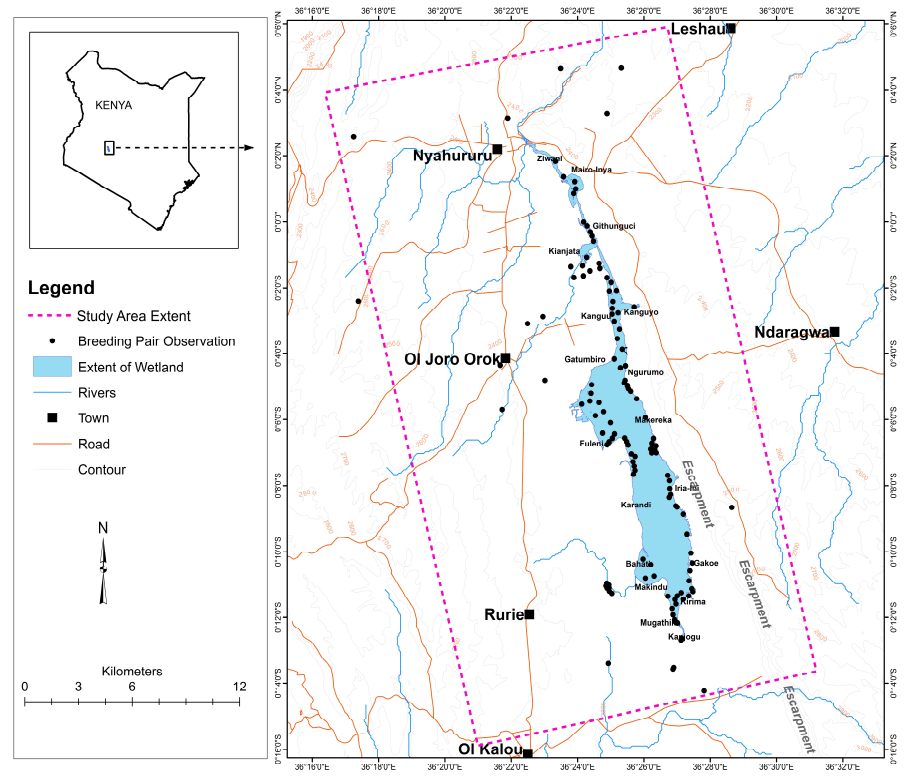

\section{Hosted file}

Figure 5 - Histogram of breeding pairs.docx available at https://authorea.com/users/317648/ articles/447739-water-depth-vegetation-height-and-water-edge-distance-are-critical-innest-site-selection-for-grey-crowned-crane-at-lake-ol-bolossat-kenya 